Research Article

\title{
Supply Chain Risk Prevention and Control Based on Fuzzy Influence Diagram and Discrete Hopfield Neural Network
}

\author{
Xin Su $(\mathbb{D})$ and Maohua Zhong \\ Institute of Public Safety Research, Department of Engineering Physics, Tsinghua University, Beijing 100084, China \\ Correspondence should be addressed to Maohua Zhong; mhzhong@tsinghua.edu.cn
}

Received 2 July 2021; Revised 27 July 2021; Accepted 4 August 2021; Published 23 August 2021

Academic Editor: Daqing Gong

Copyright ( 2021 Xin Su and Maohua Zhong. This is an open access article distributed under the Creative Commons Attribution License, which permits unrestricted use, distribution, and reproduction in any medium, provided the original work is properly cited.

\begin{abstract}
Efficient and reasonable supply chain management helps enterprises improve their efficiency, reduce costs, shorten cash flow times, and reduce enterprise risks. Risk prevention and control is a safety symbol for supply chains. To explore different influence degrees of multirisk factors and multilinks on enterprises, we propose a supply chain risk prevention and control model based on a fuzzy influence diagram and Hopfield neural network. Using the model that both calculates the risk size and occurrence probability of the supply chain and allows identifying various risk prevention and control levels, the supply chain risk is evaluated both objectively and fairly. We analyzed the theoretical and practical properties of supply chain risk prevention and control models and used it in the $H$ company to illustrate this model.
\end{abstract}

\section{Introduction}

A supply chain connects logistics, capital flow, and information flow from suppliers to customers and companies to generate revenue through value-added links such as processing, packaging, and transportation [1]. Affected by market globalization, an unstable supply and demand, shortened life cycle of products and technology, turbulent external environment of enterprises, complex cooperation networks, and other factors causes the relationship of a supply chain to become increasingly complex, which has some negative characteristics. As a result, the internal and external risks of a supply chain are increasing [2-4]. Most research studies on supply chain risks have focused on the classification of trigger events, which are usually called supply chain risk and are understood as the starting point for risk identification $[5,6]$. Therefore, in supply chain risk management, risk is characterized by the probability of events and loss to the enterprise. This article postulates that supply chain risks are affected by various factors (such as the subject, object, and environment) that cause the development of a certain event to deviate from the expected activity goal. This poses a potential threat of damage and loss to upstream and downstream enterprises and even the entire supply chain [7-9].

Supply chain risks include those caused by the lack of communication and trust between enterprises and those resulting in the failure or increased loss of the entire supply chain. This involves many links, such as transportation, distribution, warehousing, loading and unloading, handling, packaging, circulation processing, information processing, and others. Deviation activities and risk events in any link cause supply disruptions and lead to the normal operation of enterprises, which causes significant losses. An effective and proper risk management approach requires appropriate and systematic methodology, knowledge, and experience [10]. Research on supply chain risk has gradually become the focus of common concern in academia and business circles and is a new research direction in supply chain management. In related studies, some researchers noted that supply chain risk is determined by its fragility. This includes environmental, institutional, supply, demand, operational process, and failure risks of preventive measures [11]. Some scholars believe that uncertainty and supply disruption caused by external factors are vital to supply chain risks, which should be included in supply chain security-management systems 
$[12,13]$. Some researchers such as Harland et al. [14], Muntaka et al. [15], Seipp et al. [16], Hezla et al. [17], Collier and Sarkis [18], and Nazifa and Ramachandran [19] studied supply chain risk from different perspectives. Jiang and Liu [20] considered supply chain scheduling optimization as a multiobjective optimization problem from the perspective of supply chain optimization to analyze the problem of risk prevention and control. This approach combines the fuzzy correlation entropy (FCE) and particle swarm optimization into an FCE-based multiobjective optimization approach. Most of the related literatures focus on a certain stage of supply chain risk management, such as risk identification and assessment, or propose prevention and control measures for certain types of specific risks. However, there is a lack of more systematic research systems on supply chain risk. In addition, supply chain risk prevention and control includes the quantitative analysis and verification research based on the model algorithm, which has been enough and needs to be further improved and explored. Based on the existing research study, this paper further discusses supply chain risk prevention and control and takes fuzzy logic and a neural network as the theoretical support [21]. We propose a supply chain risk prevention and control model based on a fuzzy influence diagram and Hopfield neural network and apply the model to specific examples. In the application process of the model, the risk sources are first analyzed, and the risk evaluation index system is established. The risk level and occurrence probability are then studied based on risk identification and attribution. Finally, the risk prevention and control level are effectively identified, and specific prevention and control strategies are postulated for the critical points of risk prevention and control. The model solves risk problems caused by "uncertainty" and "fuzziness" in the supply chain risk assessment, provides concepts and methods to identify different risk prevention and control levels, and is beneficial for enterprises to formulate supply chain risk prevention and control strategies, which has specific theoretical and practical significance.

\section{Materials and Methods}

2.1. Fuzzy Influence Diagram. An influence diagram is an excellent decision-making modeling tool established by $\mathrm{Hu}$ et al. It has the advantages of intuition and flexibility [22] and can transmit evaluation information as given by decision-makers. This helps understand and construct the relationship between the structure and variables of complex decision-making problems in uncertain environments and obtain answers through uncertain reasoning [23]. However, actual decision-making problems are often in complex and uncertain environments and coupled with the fuzziness of human thinking. This makes it difficult for decision-makers to give accurate probability values of events. Therefore, the combination of an influence diagram and fuzzy set theory is used to build a fuzzy influence diagram (FID) to provide an improved concept and method for risk decision-making research [24].

Shachter $[25,26]$ introduced influence diagrams and common probability calculation methods. From a graph theory perspective, a direct graph is composed of a node set and a direct arc set. The net is a graph with conditional data in the node and arc, and the influence graph is a net composed of a direct graph without a cycle.

It is assumed that the data graph $V=(G, \alpha)$ with $G=$ $\left(A_{m}, E\right)$ is a direct acyclic graph; $A_{m}=\left\{x_{1}, x_{2}, \ldots, x_{m}\right\}$ is a random node variable; $\alpha: A_{m}=\{1,2, \ldots, m\}$ is the node number of $G$; arc $\left(x_{i}, x_{j}\right) \in E$ with $\alpha\left(x_{i}\right)<\alpha\left(x_{j}\right)$; and the preorder influence diagram of $A_{m}=\left\{x_{1}, x_{2}, \ldots, x_{m}\right\}$ is a data diagram $V=(G, \alpha)$, which has $(m-1)$ conditions and is independent of $A_{m}\left(X_{r} \perp\left\{x_{j} \mid \alpha\left(x_{j}\right)<\alpha\left(x_{r}\right)\right\} \mid P\left(x_{r}\right)\right.$ for $\left.\alpha\left(x_{r}\right)=2,3, \ldots, m\right)$. Here, $P\left(x_{r}\right) \subseteq\left\{x_{j}\left|\alpha\left(x_{j}\right)<\right| \alpha\left(x_{r}\right)\right\}$ and $x_{i} \in p\left(x_{r}\right) \rightleftarrows\left(x_{i}, x_{r}\right) \in E$. If $Q\left(x_{j}\right)$ is a set of nodes $x_{j}$ and there is no direct graph from $x_{i}$ to $x_{j}$ in $A_{m}$, then $x_{i} \perp Q\left(x_{j}\right) \mid P\left(x_{i}\right)$ where $P\left(x_{i}\right)$ is the direct compact prenode of $x_{i}$.

When solving the influence diagram, the most challenging step is to establish the edge probability of each node and the conditional probability between nodes. A probability distribution is often based on empirical speculation or subjective estimation, indicating it cannot easily obtain an accurate probability of variables or conditional probability between them. In addition, solving subjective probability estimations may violate probability theory. According to fuzzy set theory, a fuzzy influence diagram can overlap fuzzy sets, which solves the above problems.

The fuzzy relationship between fuzzy subsets $A$ and $B$ is as follows: $\mu_{R}\left(x_{i}, y_{j}\right)=\mu_{A \times B}\left(x_{i}, y_{j}\right)=\min \left[\mu_{A}\left(x_{i}\right), \mu_{B}\left(y_{j}\right)\right]$, where $x \in U$ and $y \in V$ with $U, V$ being the domain. The sum of the fuzzy relationship $R$ and $S$ is $R \cup S$. The eigenvalue is $\mu_{R \cup S}\left(x_{i}, y_{j}\right)=\max \left[\mu_{R}\left(x_{i}, y_{j}\right), \mu_{S}\left(x_{i}, y_{j}\right)\right]$, and the eigenvalue of the intersection of $R$ and $S(R \cap S)$ is $\mu_{R \cap S}\left(x_{i}, y_{j}\right)=\min \left[\mu_{R}\left(x_{i}, y_{j}\right), \mu_{S}\left(x_{i}, y_{j}\right)\right]$. It is necessary to quantify the linguistic variables to describe the relationship between nodes in the influence graph with fuzzy set theory, suggesting that two types of fuzzy sets should be defined. One is used to describe the event and event frequency of each independent node, and the other is used to express the fuzzy relationship between preorder and postorder nodes.

In the influence diagram (as shown in Figure 1), $X$ is an independent node of the frequency matrix, and the vector of $X$ is $P_{x}=\left(P_{x_{1}}, P_{x_{2}}, \ldots, P_{x_{n}}\right)^{T}$, where $P_{x_{1}}, P_{x_{2}}, \ldots, P_{x_{n}}$ are the fuzzy event sets defined by the linguistic variables.

It is assumed that the frequency vector of the independent node $X$ is as follows:

$$
f_{x}=\left(f_{x_{1}}, f_{x_{2}}, \ldots, f_{x_{n}}\right)^{T},
$$

where $f_{x_{1}}, f_{x_{2}}, \ldots, f_{x_{n}}$ are frequency fuzzy sets that correspond to each possible state in the frequency vector of node $X$.

The frequency matrix $F_{x}$ of the independent node $X$ is as follows:

$$
F_{x}=\left(f_{x_{1}} \times P_{x_{1}}\right) \cup\left(f_{x_{2}} \times P_{x_{2}}\right) \cup \cdots \cup\left(f_{x_{n}} \times P_{x_{n}}\right) .
$$

If the preorder nodes of $z$ are $m$ random nodes $Y_{1}, Y_{2}, \ldots, Y_{m}$, let $F_{z p}$ denote the union of all preorder node frequency matrices of $Z$. Then, 


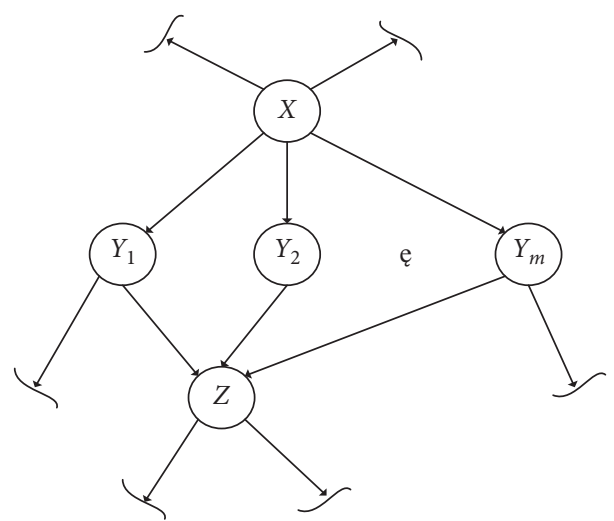

Figure 1: Schematic diagram of the impact relationship.

Step 1. Design $N$ input modes $\left\{t=t^{2}, t^{2}, \ldots, t^{N-1}, t^{N}\right\}$ and parameters $\tau$ and $h$

Step 2. Calculate $A=\left\{t^{1}-t^{N}, t^{2}-t^{N}, \ldots, t^{N-1}-t^{N}\right\}$

Step 3. Calculate the singular value decomposition $A=U S V^{T}$ and $\operatorname{rank} K-\operatorname{rank}(A)$ of $\mathrm{A}$

Step 4. Calculate $T^{P}=\sum_{I=1}^{K} u^{i}\left(u^{i}\right)^{T}$ and $T^{m}=\sum_{i=K+1}^{N} u^{i}\left(u^{i}\right)^{T}$ with $U^{P}=\left\{U^{1}, U^{2}, \ldots, U^{k}\right\}$ and $U^{m}=\left\{U^{K+1}, U^{K+2}, \ldots, U^{N}\right\}$

Step 5. Calculate $W^{t}=T^{P}-\tau \times T^{m}$ and $b^{t}=t^{N}-W^{t} \times t^{N}$

Step 6. Calculate $W=\exp \left(h \times W^{t}\right)$

Step 7. Calculate $b=U \times\left[\begin{array}{cc}C_{1} \times I(K) & 0(K, N-K) \\ 0(N-K, K) & C_{2} \times I(N-K)\end{array}\right] \times U^{T} \times b^{t}$, where $C_{1}=\exp (h)-1$ and $C_{2}=-[\exp (-\tau \times h)-1] / \tau$

Algorithm 1

$$
F_{z p}=F_{Y_{1}} \cup F_{Y_{2}} \cup F_{Y_{3}} \cup \cdots \cup F_{Y_{m}} \text {. }
$$

Let $R_{Y_{1} Z}$ denote the fuzzy relationship from node $Y_{1}$ to node $Z$. Then,

$$
R_{Y_{1} Z}=\left(P_{Y_{11}} \times P_{Z_{i}}\right) \cup\left(P_{Y_{12}} \times P_{Z_{i}}\right) \cup \cdots \cup\left(P_{Y_{1 n}} \times P_{Z_{i}}\right),
$$

where $P_{Y_{11}}, P_{Y_{12}}, \ldots, P_{Y_{1 n}} \in P_{Y_{1}}$ and $P_{Z_{i}} \in\left\{P_{Z_{1}}, P_{Z_{2}}, \ldots\right.$, $\left.P_{Z_{n}}\right\}=P_{Z}$.

The fuzzy relation from node $Y_{m}$ to node $Z$ is as follows:

$$
R_{Y_{m} Z}=\left(P_{Y_{m 1}} \times P_{Z_{i}}\right) \cup\left(P_{Y_{m 2}} \times P_{Z_{i}}\right) \cup \cdots \cup\left(P_{Y_{m n}} \times P_{Z_{i}}\right) .
$$

The union of the fuzzy relationship $R_{Y_{1} Z}, R_{Y_{2} Z}, \ldots, R_{Y_{m} Z}$ is as follows:

$$
R_{Z P}=R_{Y_{1} Z} \cup R_{Y_{2} Z} \cup \cdots \cup R_{Y_{m} Z} \cdot
$$

The frequency matrix $F_{z}$ of node $Z$ is as follows:

$$
F_{z}=F_{z p} \circ R_{z p}
$$

A row is selected from the frequency matrix $F_{Z}$ of the value node. If the sum of the membership values multiplied by its frequency is the largest in all rows, it is the membership of random results. Then, the probability function of each random result is as follows:

$$
P\left(Z_{i}\right)=\frac{\mu_{Z_{i}}}{\sum_{\Omega_{Z}} \mu_{Z_{i}}} .
$$

2.2. Hopfield Neural Network. The discrete Hopfield neural network (DHNN) and its learning algorithm were first proposed by American physicist Hopfield in 1982 [27]. The HNN uses the parallel propagation method to process data simultaneously; however, the amount of computation does not change with time. This avoids the "combinatorial explosion" problem and is superior to graph theory and programming algorithms. A fully connected neural network can simulate the memory mechanism of a biological neural network using binary neurons. Discrete values of -1 and 1 represent the neural network's output, which describes a neuron in the state of activation or inhibition. When the neuron is stimulated beyond its threshold, its state is 1; otherwise, it is -1 . The Hopfield network provides a model to simulate human memory.

2.2.1. Network Structure. The DHNN is a feedback network with a single-layer and binary output. The output of each neuron is connected to the input of the other neurons, and each node is without self-feedback. The 0th layer is used as the network input, and the first layer is the neuron, which performs the cumulative sum of the input information multiplied by the weight coefficient to produce the output information after processing by the nonlinear function $f$.

The input information is simplified to two extreme values through the threshold function $f$ (sigmoid function). If the output information of the neuron is greater than the threshold $\theta$, the neuron's input takes the value 1 ; if less, its output is -1 . The threshold function is $f(t)=\left(1+e^{-t}\right)^{-1}$. 


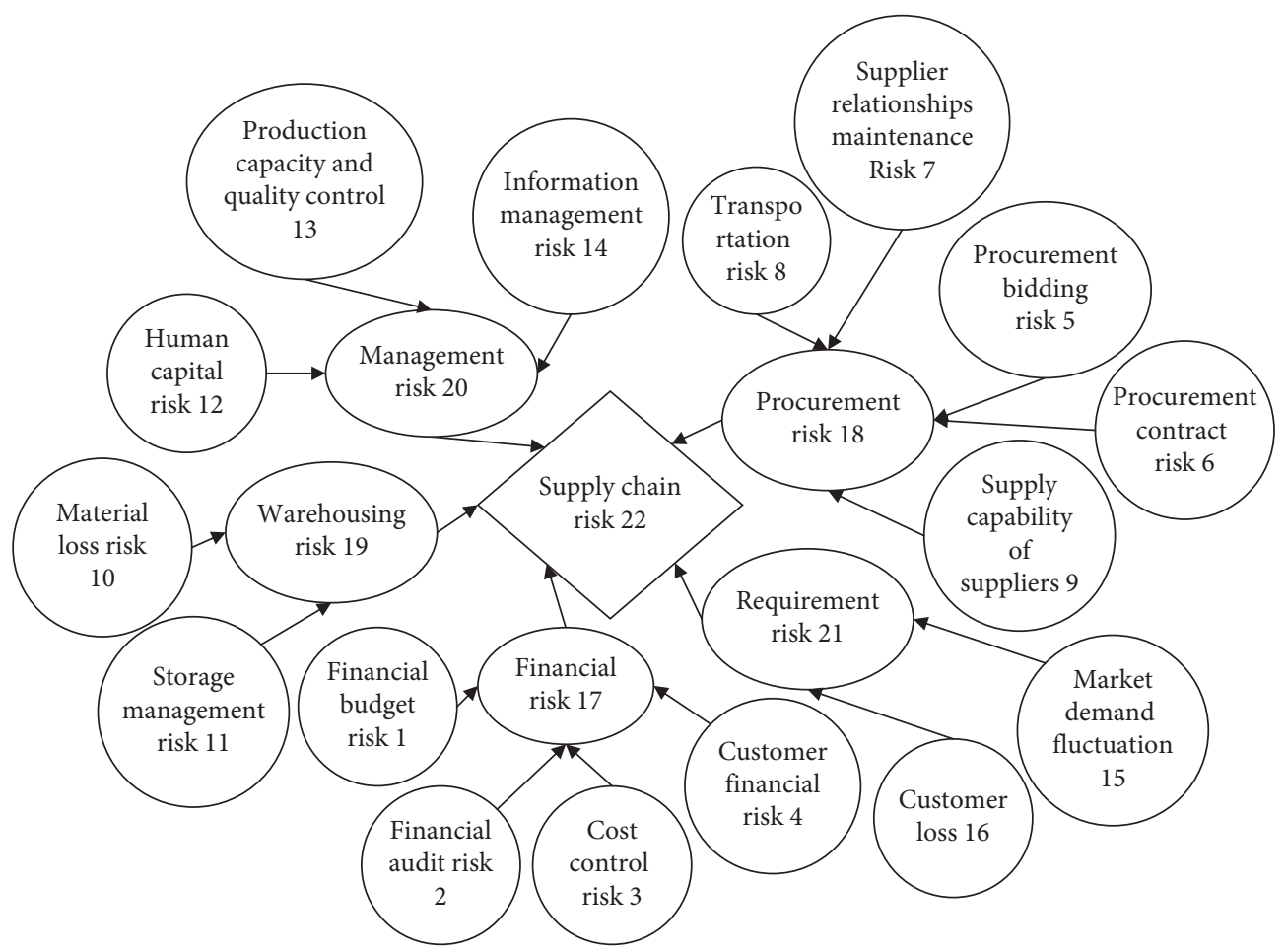

Figure 2: Risk impact diagram.

TABLE 1: Status and frequency of independent nodes.

\begin{tabular}{|c|c|c|c|c|c|c|c|c|c|c|c|}
\hline \multirow[b]{2}{*}{ Node } & \multirow[b]{2}{*}{ Name } & \multicolumn{10}{|c|}{ Possible states } \\
\hline & & $\begin{array}{c}\text { Decreases } \\
\text { more }\end{array}$ & $\begin{array}{c}\text { Slight } \\
\text { decrease }\end{array}$ & $\begin{array}{c}\text { No } \\
\text { change }\end{array}$ & $\begin{array}{c}\text { Slight } \\
\text { increase }\end{array}$ & $\begin{array}{c}\text { Increases } \\
\text { more }\end{array}$ & $\begin{array}{c}\text { Increases } \\
\text { a lot }\end{array}$ & $\begin{array}{l}\text { Increases } \\
\text { very much }\end{array}$ & Good & Middle & $\mathrm{Bad}$ \\
\hline 1 & $\begin{array}{c}\text { Financial budget } \\
\text { risk }\end{array}$ & & & Middle & & & High & Low & & & \\
\hline 2 & Financial audit risk & & & High & Low & Very low & & & & & \\
\hline 3 & Cost control risk & & & Middle & & & High & Low & & & \\
\hline 4 & $\begin{array}{l}\text { Customer financial } \\
\text { risk }\end{array}$ & & Low & & Middle & & High & & & & \\
\hline 5 & $\begin{array}{l}\text { Procurement } \\
\text { bidding risk }\end{array}$ & & & Low & & High & Very high & & & & \\
\hline 6 & $\begin{array}{c}\text { Procurement } \\
\text { contract risk } \\
\text { Supplier }\end{array}$ & & Middle & High & Middle & & & & & & \\
\hline 7 & $\begin{array}{l}\text { relationship } \\
\text { maintenance }\end{array}$ & Low & & Middle & High & & & & & & \\
\hline 8 & Transportation risk & & & & Low & Middle & High & & & & \\
\hline 9 & $\begin{array}{c}\text { Supply capability of } \\
\text { suppliers }\end{array}$ & & & & & & & & Middle & High & Middle \\
\hline 10 & Material loss risk & Very low & & & Low & Middle & High & & & & \\
\hline 11 & Storage risk & & Low & & High & Middle & & & & & \\
\hline 12 & Human capital risk & & Low & & High & Very high & Middle & & & & \\
\hline 13 & $\begin{array}{l}\text { Production capacity } \\
\text { and quality control }\end{array}$ & & & & & & & & Middle & High & Middle \\
\hline 14 & $\begin{array}{l}\text { Information } \\
\text { management risk }\end{array}$ & & & Low & & High & Very high & & & & \\
\hline 15 & $\begin{array}{l}\text { Market demand } \\
\text { fluctuation }\end{array}$ & & & Low & Middle & High & Very high & Middle & & & \\
\hline 16 & Customer loss & & & Low & Middle & High & & & & & \\
\hline
\end{tabular}


2.2.2. Network Working Mode. The Hopfield network operates dynamically, with a working process that includes the evolution of the neuron state. That is, it evolves from the initial state in the decreasing direction of "energy" (Lyapunov function) until reaching a steady-state, which is the network output.

Here, it is assumed that the operation of the Hopfield neural network is serial (asynchronous). That is, at any time $t$, only one neuron changes, while the state of other neurons remains unchanged. The network operational steps are as follows:

Step 1. Initialize the network

Step 2. Randomly select a neuron $i$ from the network

Step 3. Calculate the input $u_{i}(t)$ of neuron $i$

Step 4. Calculate the output $v_{i}(t+1)$ of neuron $i$, while the outputs of other neurons remain unchanged

Step 5. If the network reaches the stable state or satisfies the given conditions, end the evolution; otherwise, go to step 2 and continue

A network's stable state is described as unchanging from a specific time, which is called a stable network.

$$
v(t+\Delta t)=v(t) m, \quad \Delta t>0 .
$$

2.2.3. Network Stability. In a dynamic system, the steadystate can be understood as the convergence of the energy function to its minimum after decreasing continuously over the system's evolution. Thus, the sufficient conditions of the Hopfield network stability are as follows:

$$
\begin{cases}w_{i j}=0, & i=j, \\ w_{i j}=w_{j i}, & i \neq j .\end{cases}
$$

When the weight coefficient matrix $W$ is symmetric and the diagonal elements are 0 , the network is stable. Here, the orthogonalization method is selected to design the weight coefficient matrix. The weight correction method used by the newhop() function in the MATLAB neural network toolbox is the orthogonalization method, and the associated algorithm is given as follows. (Algorithm 1)

\section{Model Application}

This paper takes the $H$ company as an example, uses the risk prevention and control model to study the supply chain risk and influencing factors, and introduces risk prevention and control strategies.

3.1. Establishment of Supply Chain Risk Structure. From May 2018 to April 2019, the $H$ company implemented 12 projects involving hundreds of product parts. There were between 25 and 68 suppliers, for electrical components, sheet metal plastic parts, and other connectors.

According to the data and information of the $H$ company's supply chain issues and future development strategy, this paper sorts out all the influencing factors of their supply chain risk to the influence diagram which is drawn based on the interactions between risk factors. Each risk factor is an independent node and is the prenode of the risk event. The front node is released once the back nodes' frequency matrix is obtained in the calculation process. The topological structure of the model influence diagram for the supply chain risk influencing factors is shown in Figure 2.

\subsection{Risk Analysis Process of Supply Chain}

3.2.1. Defining Fuzzy Sets. The domain of probability is defined as $U=\{0.1,0.2,0.3,0.4,0.5,0.6,0.7,0.8,0.9,1.0\}$. Then, the frequency fuzzy set and membership degree are determined as follows:

$$
\begin{aligned}
\text { high } & =\{0.7|0.5,0.8| 0.7,0.9|0.9,1.0| 1.0\}, \\
\text { middle } & =\{0.3|0.2,0.4| 0.8,0.5|1.0,0.6| 0.8,0.7 \mid 0.2\}, \\
\text { low } & =\{0|1.0,0.1| 0.9,0.2|0.7,0.3| 0.5\}, \\
\text { very high } & =\{0.7|0.25,0.8| 0.49,0.9|0.81,1.0| 1.0\}, \\
\text { very low } & =\{0|1.0,0.1| 0.81,0.2|0.49,0.3| 0.25\} .
\end{aligned}
$$

The fuzzy set for the state and membership degree is defined as follows:

$$
\begin{aligned}
\text { decrease more } & =\{0.6|-30 \%, 1.0|-20 \%, 0.8|-10 \%, 0.4|-5 \%\}, \\
\text { slight decrease } & =\{0.6|-10 \%, 1.0|-5 \%, 0.2 \mid 0\}, \\
\text { no change } & =\{0.4|-5 \%, 1.0| 0,0.4 \mid 5 \%\}, \\
\text { slight increase } & =\{0.2|0,1.0| 5 \%, 0.6 \mid 10 \%\}, \\
\text { increase more } & =\{0.4|5 \%, 0.8| 10 \%, 1.0|20 \%, 0.6| 30 \%\}, \\
\text { icrease a lot } & =\{0.2|10 \%, 0.6| 20 \%, 0.9|30 \%, 1.0| 40 \%\}, \\
\text { increase very much } & =\{0.4|20 \%, 0.7| 30 \%, 0.9|40 \%, 1.0| 50 \%\} .
\end{aligned}
$$

Fuzzy sets do not easily describe the states of some independent nodes, or the states are deterministic values and can be fuzzed as follows:

$$
\begin{aligned}
\operatorname{good} & =\{\operatorname{good} \mid 1.0, \text { middle } \mid 0.4, \text { bad } \mid 0\}, \\
\text { middle } & =\{\operatorname{good} \mid 0.3, \text { middle } \mid 1.0, \text { bad } \mid 0.3\}, \\
\text { bad } & =\{\operatorname{good} \mid 0.0, \text { middle } \mid 0.6, \text { bad } \mid 1.0\} .
\end{aligned}
$$

The fuzzy relationship between nodes is determined based on expert suggestions. First, the random events and frequency estimates of independent nodes are described, as shown in Table 1 . Second, the fuzzy relationship between nodes is described, as shown in Table 2.

3.2.2. Calculation of Frequency Matrices of Independent Nodes. We calculate the probability distribution of nodes using the following steps: (1) independent node frequency matrix; (2) nonindependent node frequency matrix; (3) fuzzy relationship between nodes; (4) frequency matrix with compact front nodes; and (5) frequency matrix of value node. 
TABLE 2: Fuzzy relationship of risk nodes.

\begin{tabular}{|c|c|c|c|c|c|}
\hline Node & Name & $\begin{array}{c}\text { Relationship } \\
\text { nodes }\end{array}$ & Name & $\begin{array}{c}\text { Node } \\
\text { relationships }\end{array}$ & Relationship description \\
\hline 1 & Financial budget risk & 17 & Financial risk & $1 \longrightarrow 17$ & $\begin{array}{l}\text { If } 1 \text { is "no change," then } 17 \text { is "no change" } \\
\text { If } 1 \text { is "increases a lot," then } 17 \text { is "increases } \\
\text { very much" } \\
\text { If } 1 \text { is "increases very much," then } 17 \text { is } \\
\text { "increases very much" }\end{array}$ \\
\hline 2 & Financial audit risk & 17 & Financial risk & $2 \longrightarrow 17$ & $\begin{array}{l}\text { If } 2 \text { is "no change," then } 17 \text { is "no change" } \\
\text { If } 2 \text { is "slight increase," then } 17 \text { is "increases } \\
\text { more" } \\
\text { If } 2 \text { is "increases more," then } 17 \text { is "increases } \\
\text { more" }\end{array}$ \\
\hline 3 & Cost control risk & 17 & Financial risk & $3 \longrightarrow 17$ & $\begin{array}{l}\text { If } 3 \text { is "no change," then } 17 \text { is "no change" } \\
\text { If } 3 \text { is "increases a lot," then } 17 \text { is "increases } \\
\text { very much" } \\
\text { If } 3 \text { is "increases very much," then } 17 \text { is } \\
\text { "increases very much" }\end{array}$ \\
\hline 4 & Customer financial risk & 17 & Financial risk & $4 \longrightarrow 17$ & $\begin{array}{c}\text { If } 4 \text { is "slight decrease," then } 17 \text { is "no } \\
\text { change" } \\
\text { If } 4 \text { is "slight increase," then } 17 \text { is "increases } \\
\text { more" } \\
\text { If } 4 \text { is "increases a lot," then } 17 \text { is "increases } \\
\text { very much" }\end{array}$ \\
\hline 5 & Procurement tender risk & 18 & $\begin{array}{l}\text { Procurement } \\
\text { risk }\end{array}$ & $5 \longrightarrow 18$ & $\begin{array}{l}\text { If } 5 \text { is "no change," then } 17 \text { is "no change" } \\
\text { If } 5 \text { is "increases more," then } 17 \text { is "increases } \\
\text { a lot" } \\
\text { If } 5 \text { is "increases a lot," then } 17 \text { is "increases } \\
\text { very much" }\end{array}$ \\
\hline 6 & Procurement contract risk & 18 & $\begin{array}{l}\text { Procurement } \\
\text { risk }\end{array}$ & $6 \longrightarrow 18$ & $\begin{array}{l}\text { If } 6 \text { is "slight decrease," then } 18 \text { is "no } \\
\text { change" } \\
\text { If } 6 \text { is "no change," then } 18 \text { is "no change" } \\
\text { If } 6 \text { is "slight increase," then } 18 \text { is "increases } \\
\text { more" }\end{array}$ \\
\hline 7 & $\begin{array}{l}\text { Supplier relationship } \\
\text { maintenance }\end{array}$ & 18 & $\begin{array}{l}\text { Procurement } \\
\text { risk }\end{array}$ & $7 \longrightarrow 18$ & $\begin{array}{l}\text { If } 7 \text { is "decreases more," then } 18 \text { is "slight } \\
\text { decrease" } \\
\text { If } 7 \text { is "no change," then } 18 \text { is "no change" } \\
\text { If } 7 \text { is "slight increase," then } 18 \text { is "increases } \\
\text { more" }\end{array}$ \\
\hline 8 & Transportation risk & 18 & $\begin{array}{l}\text { Procurement } \\
\text { risk }\end{array}$ & $8 \longrightarrow 18$ & $\begin{array}{l}\text { If } 8 \text { is "slight increase," then } 18 \text { is "increases } \\
\text { more" } \\
\text { If } 8 \text { is "increases more," then } 18 \text { is "increases } \\
\text { a lot" } \\
\text { If } 8 \text { is "increases more," then } 18 \text { is "increases } \\
\text { very much" }\end{array}$ \\
\hline 9 & Supply capability of suppliers & 18 & $\begin{array}{l}\text { Procurement } \\
\text { risk }\end{array}$ & $9 \longrightarrow 18$ & $\begin{array}{l}\text { If } 9 \text { is "good," then } 18 \text { is "no change" } \\
\text { If } 9 \text { is "middle," then } 18 \text { "slight increase" } \\
\text { If } 9 \text { is "bad," then } 18 \text { is "increases a lot" }\end{array}$ \\
\hline 10 & Material loss risk & 19 & $\begin{array}{l}\text { Warehousing } \\
\text { risk }\end{array}$ & $10 \longrightarrow 19$ & $\begin{array}{l}\text { If } 10 \text { is "decreases more," then } 19 \text { is } \\
\text { "increases a lot" } \\
\text { If } 10 \text { is "slight increase," then } 19 \text { is } \\
\text { "increases more" } \\
\text { If } 10 \text { is "increases more," then } 19 \text { is } \\
\text { "increases a lot" } \\
\text { If } 10 \text { is "increases a lot," then } 19 \text { is } \\
\text { "increases very much" }\end{array}$ \\
\hline
\end{tabular}


TABle 2: Continued.

\begin{tabular}{|c|c|c|c|c|c|}
\hline Node & Name & $\begin{array}{l}\text { Relationship } \\
\text { nodes }\end{array}$ & Name & $\begin{array}{c}\text { Node } \\
\text { relationships }\end{array}$ & Relationship description \\
\hline 11 & Storage risk & 19 & $\begin{array}{l}\text { Warehousing } \\
\text { risk }\end{array}$ & $11 \longrightarrow 19$ & $\begin{array}{l}\text { If } 11 \text { is "slight decrease," then } 19 \text { is "no } \\
\text { change" } \\
\text { If } 11 \text { is "slight increase," then } 19 \text { is } \\
\text { "increases a lot" } \\
\text { If } 11 \text { is "increases more," then } 19 \text { is } \\
\text { "increases a lot" }\end{array}$ \\
\hline 12 & Human capital risk & 20 & $\begin{array}{l}\text { Management } \\
\text { risk }\end{array}$ & $12 \longrightarrow 20$ & $\begin{array}{l}\text { If } 12 \text { is "slight decrease," then } 20 \text { is "no } \\
\text { change" } \\
\text { If } 12 \text { is "slight increase," then } 20 \text { is } \\
\text { "increases more" } \\
\text { If } 12 \text { is "increases more," then } 20 \text { is } \\
\text { "increases a lot" } \\
\text { If } 12 \text { is "increases a lot," then } 20 \text { is } \\
\text { "increases very much" }\end{array}$ \\
\hline 13 & $\begin{array}{c}\text { Production capacity and } \\
\text { quality control }\end{array}$ & 20 & $\begin{array}{l}\text { Management } \\
\text { risk }\end{array}$ & $13 \longrightarrow 20$ & $\begin{array}{l}\text { If } 2 \text { is "good," then } 20 \text { is "no change" } \\
\text { If } 2 \text { is "middle," then } 20 \text { is "slight increase" } \\
\text { If } 2 \text { is "bad," then } 20 \text { is "increases a lot" }\end{array}$ \\
\hline 14 & Information management risk & 20 & $\begin{array}{l}\text { Management } \\
\text { risk }\end{array}$ & $14 \longrightarrow 20$ & $\begin{array}{l}\text { If } 14 \text { is "no change," then } 20 \text { is "no change" } \\
\text { If } 14 \text { is "increases more," then } 20 \text { is } \\
\text { "increases a lot" } \\
\text { If } 14 \text { is "increases a lot," then } 20 \text { is } \\
\text { "increases very much" }\end{array}$ \\
\hline 15 & Market demand fluctuation & 21 & $\begin{array}{l}\text { Requirement } \\
\text { risk }\end{array}$ & $15 \longrightarrow 21$ & $\begin{array}{l}\text { If } 15 \text { is "no change," then } 21 \text { is "no change" } \\
\text { If } 15 \text { is "slight increase," then } 21 \text { is } \\
\text { "increases more" } \\
\text { If } 15 \text { is "increases more," then } 21 \text { is } \\
\text { "increases a lot" } \\
\text { If } 15 \text { is "increases a lot," then } 21 \text { is "increases } \\
\text { very much" } \\
\text { If } 15 \text { is "increases very much," then } 21 \text { is } \\
\text { "increases very much" }\end{array}$ \\
\hline 16 & Customer loss & 21 & $\begin{array}{l}\text { Requirement } \\
\text { risk }\end{array}$ & $16 \longrightarrow 21$ & $\begin{array}{l}\text { If } 16 \text { is "no change," then } 21 \text { is "no change" } \\
\text { If } 16 \text { is "slight increase," then } 21 \text { is } \\
\text { "increases more" } \\
\text { If } 16 \text { is "increases more," then } 21 \text { is } \\
\text { "increases a lot" }\end{array}$ \\
\hline 17 & Financial risk & 22 & $\begin{array}{l}\text { Supply chain } \\
\text { risk }\end{array}$ & $17 \longrightarrow 22$ & $\begin{array}{l}\text { If } 17 \text { is "slight decrease," then } 22 \text { is "no } \\
\text { change" } \\
\text { If } 17 \text { is "no change," then } 22 \text { is "no change" } \\
\text { If } 17 \text { is "slight increase," then } 22 \text { is } \\
\text { "increases more" } \\
\text { If } 17 \text { is "increases more," then } 22 \text { is } \\
\text { "increases a lot" } \\
\text { If } 17 \text { is "increases a lot," then } 22 \text { is } \\
\text { "increases very much" } \\
\text { If } 17 \text { is "increases very much," then } 22 \text { is } \\
\text { "increases very much" }\end{array}$ \\
\hline 18 & Procurement risk & 22 & $\begin{array}{l}\text { Supply chain } \\
\text { risk }\end{array}$ & $18 \longrightarrow 22$ & $\begin{array}{l}\text { If } 18 \text { is "decreases more," then } 22 \text { is "slight } \\
\text { decrease" } \\
\text { If } 18 \text { is "slight decrease," then } 22 \text { is "no } \\
\text { change" } \\
\text { If } 18 \text { is "no change," then } 22 \text { is "no change" } \\
\text { If } 18 \text { is "slight increase," then } 22 \text { is } \\
\text { "increases more" } \\
\text { If } 18 \text { is "increases more," then } 22 \text { is } \\
\text { "increases a lot" } \\
\text { If } 18 \text { is "increases a lot," then } 22 \text { is } \\
\text { "increases very much" }\end{array}$ \\
\hline
\end{tabular}


TABle 2: Continued.

\begin{tabular}{|c|c|c|c|c|c|}
\hline Node & Name & $\begin{array}{c}\text { Relationship } \\
\text { nodes }\end{array}$ & Name & $\begin{array}{c}\text { Node } \\
\text { relationships }\end{array}$ & Relationship description \\
\hline 19 & Warehousing risk & 22 & $\begin{array}{l}\text { Supply chain } \\
\text { risk }\end{array}$ & $19 \longrightarrow 22$ & $\begin{array}{l}\text { If } 19 \text { is "decreases more," then } 22 \text { is "slight } \\
\text { decrease" } \\
\text { If } 19 \text { is "slight decrease," then } 22 \text { is "no } \\
\text { change" } \\
\text { If } 19 \text { is "slight increase," then } 22 \text { is } \\
\text { "increases more" } \\
\text { If } 19 \text { is "increases a lot," then } 22 \text { is } \\
\text { "increases very much" }\end{array}$ \\
\hline 20 & Management risk & 22 & $\begin{array}{l}\text { Supply chain } \\
\text { risk }\end{array}$ & $20 \longrightarrow 22$ & $\begin{array}{l}\text { If } 20 \text { is "slight decrease," then } 22 \text { is "no } \\
\text { change" } \\
\text { If } 20 \text { is "no change," then } 22 \text { is "no change" } \\
\text { If } 20 \text { is "slight increase," then } 22 \text { is } \\
\text { "increases a lot" } \\
\text { If } 20 \text { is "increases a lot," then } 22 \text { is } \\
\text { "increases very much" }\end{array}$ \\
\hline 21 & Requirement risk & 22 & $\begin{array}{l}\text { Supply chain } \\
\text { risk }\end{array}$ & $21 \longrightarrow 22$ & $\begin{array}{l}\text { If } 21 \text { is "no change," then } 22 \text { is "no change" } \\
\text { If } 21 \text { is "slight decrease," then } 22 \text { is } \\
\text { "increases more" } \\
\text { If } 21 \text { is "increases more," then } 22 \text { is } \\
\text { "increases a lot" } \\
\text { If } 21 \text { is "increases a lot," then } 22 \text { is "increases } \\
\text { very much" } \\
\text { If } 21 \text { is "increases very much," then } 22 \text { is } \\
\text { "increases very much" }\end{array}$ \\
\hline
\end{tabular}

TABle 3: Probability distribution of value node.

\begin{tabular}{lccc}
\hline Risk probability & Membership degree & Probability & Cumulative probability \\
\hline$-10 \%$ & 0.24 & 0.036145 & 0.036145 \\
$-5 \%$ & 0.4 & 0.060241 & 0.096386 \\
$0 \%$ & 1.0 & 0.150602 & 0.246988 \\
$5 \%$ & 0.4 & 0.060241 & 0.307229 \\
$10 \%$ & 0.8 & 0.120482 & 0.427711 \\
$20 \%$ & 0.8 & 0.120482 & 0.548193 \\
$30 \%$ & 1.0 & 0.150602 & 0.698795 \\
$40 \%$ & 1.0 & 0.150602 & 0.849398 \\
$50 \%$ & 1.0 & 0.150602 & 1 \\
\hline
\end{tabular}

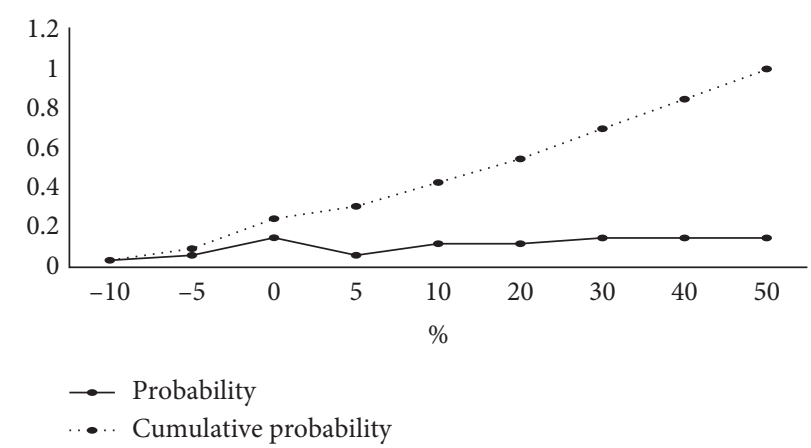

Figure 3: Probability distribution and cumulative probability of value nodes. 


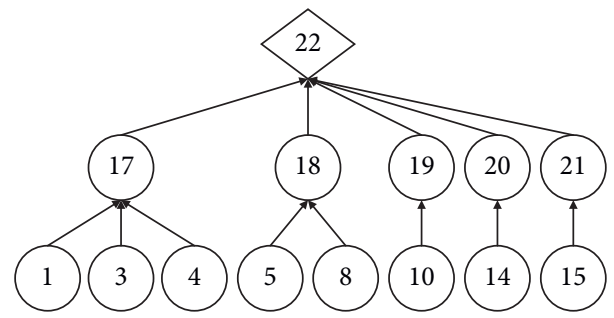

Figure 4: Risk impact levels.

According to equation (2), the frequency matrices of independent nodes are calculated and the nodes are released. The frequency matrices of $F^{(1)}-F^{(16)}$ are as follows:

\begin{tabular}{|c|c|c|c|c|c|c|c|c|c|c|c|c|c|c|}
\hline$-30 \%$ & $-20 \%$ & $-10 \%$ & $-5 \%$ & 0 & $5 \%$ & $10 \%$ & $20 \%$ & $30 \%$ & $40 \%$ & $50 \%$ & B & $M$ & G & \\
\hline 0.0 & $0.6^{(7,10)}$ & $1^{(7.10)}$ & $\begin{array}{c}0.6^{(4,11,12)} \\
0.8^{(7,10)}\end{array}$ & $\begin{array}{c}0.4^{(5,10,14,15,16)} \\
1^{(4,11,12)}\end{array}$ & $\begin{array}{c}0.2^{(2,4.8,10,11,12)} \\
1^{(5,14,15,16)}\end{array}$ & $\begin{array}{c}0.4^{(5,14,15,16)} \\
1^{(2,8,10)}\end{array}$ & $\begin{array}{c}0.6^{(8,10)} \\
0.8^{(2)}\end{array}$ & $\begin{array}{c}0.4^{(1,3)} \\
1^{(2)}\end{array}$ & $\begin{array}{c}0.6^{2} \\
0.7^{(1,3)}\end{array}$ & $0.9^{(1,3)}$ & $1^{(1,3)}$ & 0 & 0 & 0 \\
\hline 0.1 & $\begin{array}{c}0.486^{(10)} \\
0.54^{(7)}\end{array}$ & $\begin{array}{c}0.81^{(10)} ; \\
0.9^{(7)}\end{array}$ & $\begin{array}{c}0.148^{(10)} \\
0.54^{(4,11,12)} \\
0.72^{(7)}\end{array}$ & $\begin{array}{c}0.324^{(10)} \\
0.36^{(5,14,15,16)} \\
0.9^{(4,11,12)}\end{array}$ & $\begin{array}{c}0.18^{(2,4,8,10,11,12)} \\
0.9^{(5,14,15,16)}\end{array}$ & $\begin{array}{c}0.36^{(5,14,15,16)} \\
0.9^{(2,8,10)}\end{array}$ & $\begin{array}{c}0.54^{(8,10)} \\
0.648^{(2)}\end{array}$ & $\begin{array}{c}0.36^{(1,3)} \\
0.81^{(2)}\end{array}$ & $\begin{array}{l}0.486^{(2)} \\
0.63^{(1.3)}\end{array}$ & $0.81^{(1,3)}$ & $0.9^{(1,3)}$ & 0 & 0 & 0 \\
\hline 0.2 & $\begin{array}{c}0.294^{(10)} \\
0.42^{(7)}\end{array}$ & $\begin{array}{c}0.49^{(10)} \\
0.7^{(7)}\end{array}$ & $\begin{array}{c}0.392^{(10)} \\
0.42^{(4,11,12)} \\
0.56^{(7)}\end{array}$ & $\begin{array}{c}0.196^{(10)} ; \\
0.28^{(5,14,15,16)} ; \\
0.7^{(4,11,12)}\end{array}$ & $\begin{array}{c}0.14^{(2,4,8,10,11,12)} \\
0.7^{(5,14,15,16)}\end{array}$ & $\begin{array}{c}0.28^{(5,14,15,16)} \\
0.7^{(2,8,10)}\end{array}$ & $0.42^{(2,8,10)}$ & $\begin{array}{c}0.28^{(1,3)} \\
0.49^{(2)}\end{array}$ & $\begin{array}{l}0.294^{(2)} \\
0.49^{(1,3)}\end{array}$ & $0.63^{(1,3)}$ & $\begin{array}{c}0.7^{(3)} \\
1^{(1)}\end{array}$ & 0 & 0 & 0 \\
\hline 0.3 & $\begin{array}{c}0.15^{(10)} \\
0.3^{(7)}\end{array}$ & $\begin{array}{c}0.25^{(10)} \\
0.5^{(7)}\end{array}$ & $\begin{array}{c}0.12^{(6)} \\
0.2^{(10)} \\
0.3^{(4,11,12)} \\
0.4^{(7)}\end{array}$ & $\begin{array}{c}0.08^{(3)} ; \\
0.1^{(10)} ; \\
0.12^{(1)} ; \\
0.2^{(5,6,7,14,15,16)} ; \\
0.5^{(4,11,12)}\end{array}$ & $\begin{array}{c}0.04^{(6)} \\
0.1^{(2,4,8,10,11,12)} \\
0.2^{(1,3,7)} \\
0.5^{(5,14,15,16)}\end{array}$ & $\begin{array}{c}0.08^{(3,7,11)} \\
0.12^{(1)} \\
0.2^{(4,5,6,14,15,16)} \\
0.5^{(2,8,10)}\end{array}$ & $\begin{array}{c}0.04^{(12)} ; \\
0.12^{(4,6,15,16)} ; \\
0.16^{(11)} ; \\
0.3^{(2,8,10)}\end{array}$ & $\begin{array}{c}0.08^{(15)} ; \\
0.12^{(12)} ; \\
0.2^{(1,3,8,10,11)} ; \\
0.25^{(2)}\end{array}$ & $\begin{array}{c}0.12^{(8,10,11)} \\
0.14^{(15)} \\
0.15^{(2)} \\
0.18^{(12)} \\
0.35^{(13)}\end{array}$ & $\begin{array}{l}0.18^{(15)} \\
0.2^{(12)} \\
0.45^{(1,3)}\end{array}$ & $\begin{array}{l}0.2^{(15)} \\
0.5^{(1,3)}\end{array}$ & $0.2^{(9,13)}$ & $0.06^{(9,13)}$ & $0.2^{(9,13)}$ \\
\hline 0.4 & 0 & 0 & $0.48^{(6)}$ & $\begin{array}{c}0.32^{(3,7)} \\
0.48^{(1)} \\
0.8^{(6)}\end{array}$ & $\begin{array}{c}0.16^{(4,6.15,16)} \\
0.8^{(1,3,7)}\end{array}$ & $\begin{array}{c}0.32^{(3,7,8,10,11)} \\
0.48^{(1)} \\
0.8^{(4,6,15,16)}\end{array}$ & $\begin{array}{c}0.16^{(12)} ; \\
0.48^{(4,6,15,16)} \\
0.64^{(8,10,11)}\end{array}$ & $\begin{array}{c}0.32^{(15)} \\
0.48^{(12)} \\
0.8^{(8,10,11)}\end{array}$ & $\begin{array}{c}0.48^{(8,10,11)} \\
0.56^{(15)} \\
0.72^{(12)}\end{array}$ & $\begin{array}{c}0.72^{(15)} \\
0.8^{(12)}\end{array}$ & $0.8^{(15)}$ & $0.8^{(9,13)}$ & $0.24^{(9,13)}$ & $0.8^{(9,13)}$ \\
\hline 0.5 & 0 & 0 & $0.6^{(6)}$ & $\begin{array}{c}0.4^{(3.7)} \\
0.6^{(1)} \\
1^{(6)}\end{array}$ & $\begin{array}{c}0.2^{(4,6,15,16)} \\
1^{(1,3,7)}\end{array}$ & $\begin{array}{c}0.4^{(3,7.8,10,11)} \\
0.6^{(1)} \\
1^{(4,6,15,16)}\end{array}$ & $\begin{array}{c}0.2^{(12)} \\
0.6^{(4,6,15,16)} \\
0.8^{(8,10,11)}\end{array}$ & $\begin{array}{l}0.4^{(15)} \\
0.6^{(12)} \\
1^{(8,10,11)}\end{array}$ & $\begin{array}{c}0.6^{(8,10,11)} \\
0.7^{(15)} \\
0.9^{(12)}\end{array}$ & $\begin{array}{c}0.9^{(15)} \\
1^{(12)}\end{array}$ & $1^{(15)}$ & $1^{(9,13)}$ & $0.3^{(9,13)}$ & $1^{(9,13)}$ \\
\hline 0.6 & 0 & 0 & $0.48^{(6)}$ & $\begin{array}{c}0.32^{(3,7)} \\
0.48^{(1)} \\
0.8^{(6)}\end{array}$ & $\begin{array}{c}0.16^{(4.6,15,16)} \\
0.8^{(1,3,7)}\end{array}$ & $\begin{array}{c}0.32^{(3,7,8,10)} \\
0.48^{(1)} \\
0.8^{(4,6,6,15,16)}\end{array}$ & $\begin{array}{c}0.16^{(12)} ; \\
0.48^{(4,6,15,16)} \\
0.64^{(8,10)}\end{array}$ & $\begin{array}{c}0.32^{(15)} \\
0.48^{(12)} \\
0.8^{(8,10,11)}\end{array}$ & $\begin{array}{c}0.48^{(8,10,11)} \\
0.56^{(15)} \\
0.72^{(12)}\end{array}$ & $\begin{array}{c}0.72^{(15)} \\
0.8^{(12)}\end{array}$ & $0.8^{(15)}$ & $0.8^{(9,13)}$ & $0.24^{(9,13)}$ & $0.8^{(9,13)}$ \\
\hline 0.7 & 0 & 0 & $0.12^{(6)}$ & $\begin{array}{c}0.08^{(3,7)} \\
0.12^{(1)} \\
0.2^{(2,6)}\end{array}$ & $\begin{array}{c}0.04^{(4,15,16)} \\
0.1^{(11,12)} \\
0.2^{(1,3,7)} \\
0.5^{(2,6)}\end{array}$ & $\begin{array}{c}0.08^{(3,8,10)} ; \\
0.12^{(1)} ; \\
0.2^{(2,4,6,5,14,15,16)} ; \\
0.5^{(7,11,12)}\end{array}$ & $\begin{array}{c}0.1^{(1,3)} ; \\
0.12^{(4,6)} ; \\
0.16^{(8,10)} ; \\
0.3^{(7,11,12)} \\
0.4^{(5,14,15,16)}\end{array}$ & $\begin{array}{c}0.2^{(11)} ; \\
0.25^{(12)} ; \\
0.3^{(1,3,4,8,10)} ; \\
0.5^{(5,14,15,16)}\end{array}$ & $\begin{array}{c}0.12^{(11)} ; \\
0.18^{(12)} \\
0.3^{(5,14,15,16)} \\
0.45^{(1,3,4,8,10)} \\
0.525^{(14)}\end{array}$ & $\begin{array}{c}0.2^{(12)} ; \\
0.25^{(5,14,15)} \\
0.5^{(1,3,4,8,8,10)}\end{array}$ & $0.2^{(15)}$ & $0.3^{(9,13)}$ & $0.5^{(9,13)}$ & $0.2^{(9,13)}$ \\
\hline 0.8 & 0 & 0 & 0 & $0.28^{(2,6)}$ & $\begin{array}{c}0.14^{(7,11,12)} \\
0.7^{(2,6)}\end{array}$ & $\begin{array}{c}0.28^{(2,5,6,14,15,16)} \\
0.7^{(7,11,12)}\end{array}$ & $\begin{array}{c}0.14^{(1,3,4,8,10)} \\
0.42^{(7,11,12)} \\
0.56^{(5,14,15.16)}\end{array}$ & $\begin{array}{c}0.42^{(1,3,4,8,10)} ; \\
0.49^{(12)} ; \\
0.7^{(5,14,15,16)}\end{array}$ & $\begin{array}{c}0.294^{(12)} ; \\
0.42^{(16)} ; \\
0.441^{(5,14,15)} \\
0.63^{(1,3,4,8,10)}\end{array}$ & $\begin{array}{l}0.49^{(5,14,15)} \\
0.7^{(1,3,4,8,10)}\end{array}$ & 0 & $0.42^{(9,13)}$ & $0.7^{(9,13)}$ & $0.28^{(9,13)}$ \\
\hline 0.9 & 0 & 0 & 0 & $0.36^{(2,6)}$ & $\begin{array}{c}0.18^{(7,11,12)} \\
0.9^{(2,6)}\end{array}$ & $\begin{array}{c}0.36^{(2,5,6,14,15,16)} \\
0.9^{(7,11,12)}\end{array}$ & $\begin{array}{c}0.18^{(1,3,4,8,10)} \\
0.54^{(7,11)} ; \\
0.648^{(12)} ; \\
0.72^{(5,14,15,16)} \\
0.882^{(15)}\end{array}$ & $\begin{array}{c}0.54^{(1,3,4,8,10)} ; \\
0.81^{(12)} ; \\
0.9^{(5,14,15,16)}\end{array}$ & $\begin{array}{c}0.486^{(12)} ; \\
0.54^{(16)} ; \\
0.729^{(5,14,15)} \\
0.81^{(1,3,4,8,10)}\end{array}$ & $\begin{array}{l}0.81^{(5,14,15)} \\
0.9^{(1,3,4.8,10)}\end{array}$ & 0 & $0.54^{(9,13)}$ & $0.9^{(9,13)}$ & $0.36^{(9,13)}$ \\
\hline 1.0 & 0 & 0 & 0 & $0.4^{(2,6)}$ & $\begin{array}{c}0.2^{(7,11,12)} \\
1^{(2,6)}\end{array}$ & $\begin{array}{c}0.4^{(2,5,6,14,15,16)} \\
1^{(7,11,12)}\end{array}$ & $\begin{array}{c}0.2^{(1,3,4,8,10)} \\
0.6^{(7,11)} \\
0.8^{(5,12,14,15,16)} \\
1^{(15)}\end{array}$ & $\begin{array}{l}0.6^{(1,3,4,8,10)} \\
1^{(5,12,14,15,16)}\end{array}$ & $\begin{array}{c}0.6^{(12,16)} \\
0.9^{(1,3,4,5,8,10,14,15)}\end{array}$ & $1^{(1,3,4,5,5,8,10,14,15)}$ & 0 & $0.6^{(9,13)}$ & $1^{(9,13)}$ & $0.4^{(9,13)}$ \\
\hline
\end{tabular}

3.2.3. Calculation of Frequency Matrices for Nonindependent Nodes. To calculate the frequency matrices of nonindependent nodes, it is necessary to calculate their union and fuzzy relationship union for the prenodes. The joint frequency matrices of $F^{(17)}, F^{(18)}, F^{(19)}, F^{(20)}, F^{(21)}$, and $F^{(22)}$ are calculated from equation (3). $F^{(17 A)}=F^{(1)} \cup F^{(2)} \cup$ $F^{(3)} \cup F^{(4)} ; F^{(18 A)}=F^{(5)} \cup F^{(6)} \cup F^{(7)} \cup F^{(8)} \cup F^{(9)} ; F^{(19 A)}=$ $F^{(10)} \cup F^{(11)} ; \quad F^{(20 A)}=F^{(12)} \cup F^{(13)} \cup F^{(14)} ; \quad F^{(21 A)} \quad=$ 


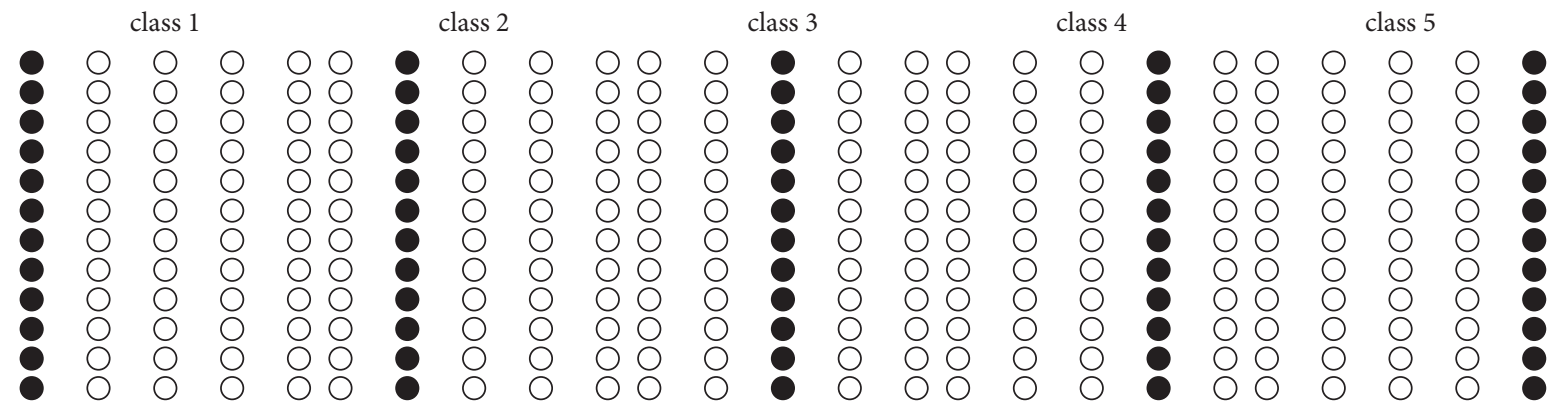

FIGURE 5: Equilibrium point coding.

$F^{(15)} \cup F^{(16)} ; \quad$ and $\quad F^{(22 A)}=F^{(17)} \cup F^{(18)} \cup F^{(19)} \cup \quad F^{(20)}$ $\cup F^{(21)}$.
The associated frequency matrix union is as follows:

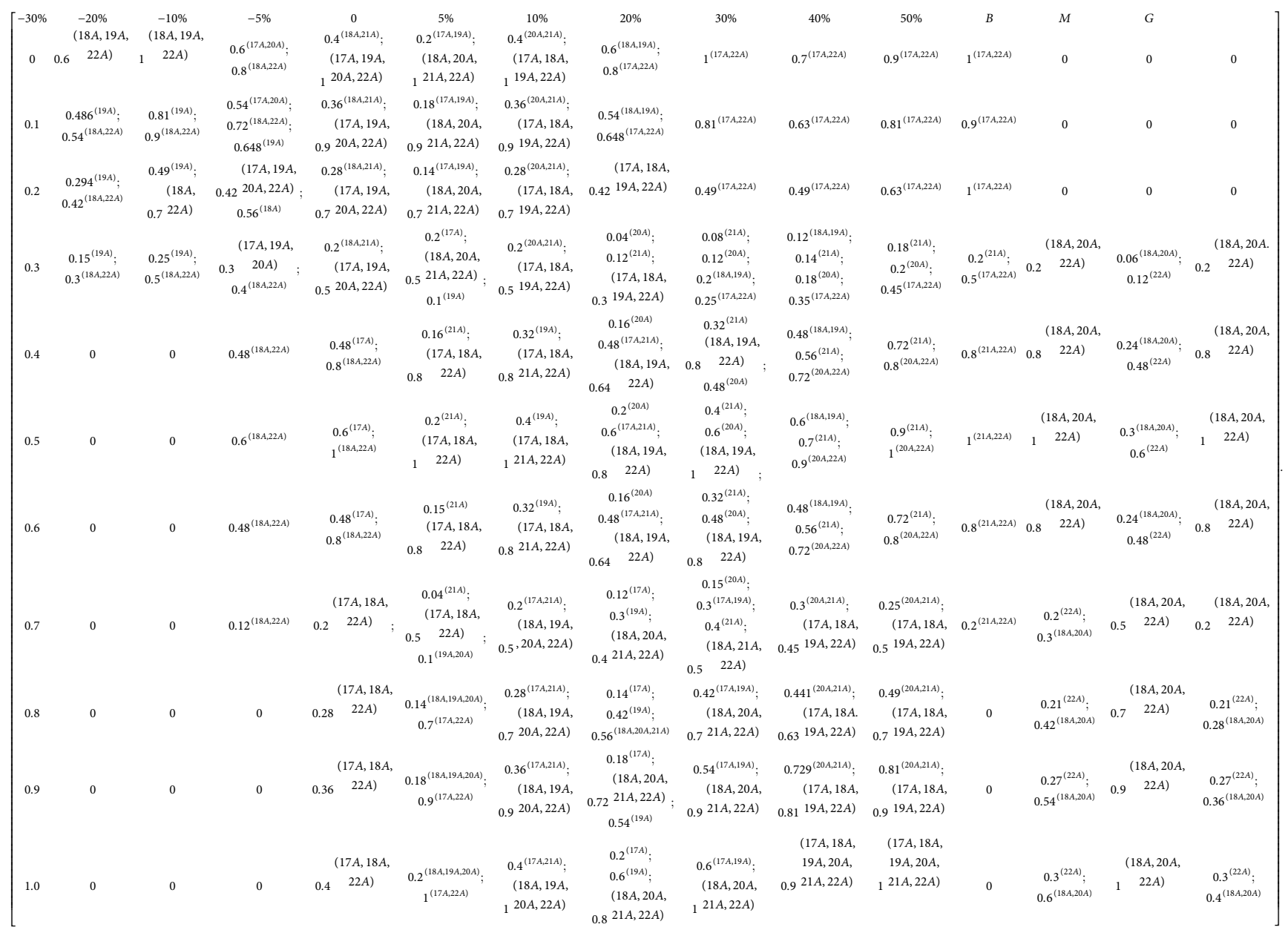




\begin{tabular}{|c|c|c|c|c|c|c|c|c|c|c|c|c|c|c|c|}
\hline prescrpc 1 & prescrpc 2 & prescrpc 3 & prescrpc 4 & prescrpc 5 & prescrpc 6 & prescrpc 7 & prescrpc 8 & prescrpc 9 & prescrpc 10 & prescrpc 11 & prescrpc 12 & prescrpc 13 & prescrpc 14 & prescrpc 15 & prescrpc 16 \\
\hline 00000 & .00000 & $00 \times 00$ & 00000 & 0000 & .0000 & 00000 & 00000 & 00000 & 00000 & 00000 & 00000 & 00000 & $\infty 000$ & $\infty 000$ & 00000 \\
\hline 00000 & .00000 & 00000 & 00000 & $\infty$ & .0000 & 00000 & 00000 & 00000 & 00000 & 00000 & 00000 & 00000 & 00000 & $\infty 000$ & 00000 \\
\hline 00000 & 00000 & 00000 & 00000 & 00000 & 00000 & 00000 & $\infty 000 \bullet$ & 00000 & 00000 & 00000 & 00000 & 00000 & 0000 & $\infty 000$ & $\infty 0000$ \\
\hline 00000 & 00000 & 00000 & $\infty 0000$ & 0000 & 00000 & 00000 & 00000 & .0000 & 00000 & 00000 & 00000 & 00000 & $\infty 000$ & 00000 & 00000 \\
\hline 00000 & 00000 & 00000 & 00000 & 00000 & 00000 & 00000 & 00000 & 00000 & 00000 & 00000 & 00000 & 100000 & 0000 & 0000 & $\infty 0000$ \\
\hline 00000 & .0000 & 00000 & 00000 & $\infty 000$ & .0000 & .0000 & 00000 & 00000 & 00000 & 00000 & 00000 & 00000 & 0000 & 00000 & 00000 \\
\hline .0000 & 00000 & 100000 & 00000 & $\infty 000$ & .0000 & 00000 & 00000 & 00000 & 00000 & 00000 & 00000 & 00000 & 0000 & $\infty 000$ & 00000 \\
\hline 00000 & .0000 & 00000 & 00000 & 00000 & .0000 & 00000 & 00000 & 00000 & 00000 & .0000 & 00000 & 00000 & 00000 & $\infty 0000$ & 00000 \\
\hline 00000 & .0000 & $00 \times 0$ & $\infty 0000$ & 00000 & .0000 & 00000 & 00000 & 00000 & 00000 & 00000 & 00000 & 00000 & 0000 & 00000 & 00000 \\
\hline 00000 & .00000 & 00000 & 00000 & $\infty 000$ & 00000 & 00000 & 00000 & .0000 & 00000 & 00000 & 00000 & 00000 & 00000 & 0000 & $\infty 0000$ \\
\hline 00000 & .0000 & 00000 & 00000 & $\infty 000$ & 00000 & 00000 & 00000 & 00000 & 00000 & 00000 & 00000 & 00000 & 00000 & $\infty 000$ & 00000 \\
\hline 00000 & 00000 & 00000 & 00000 & 00000 & .0000 & 00000 & 00000 & 00000 & 00000 & 00000 & 00000 & 00000 & 00000 & 00000 & 00000 \\
\hline scrpc 1 & scrpc 2 & $\operatorname{scrpc} 3$ & $\operatorname{scrpc} 4$ & $\operatorname{scrpc} 5$ & $\operatorname{scrpc} 6$ & scrpc 7 & $\operatorname{scrpc} 8$ & $\operatorname{scrpc} 9$ & scrpc 10 & scrpc 11 & scrpc 12 & scrpc 13 & scrpc 14 & scrpc 15 & scrpc 16 \\
\hline 00000 & .00000 & $\infty 0 \times 0$ & $\infty 0000$ & $\infty 000$ & .0000 & 00000 & 00000 & 00000 & 00000 & 00000 & 00000 & 00000 & $\infty 000$ & $\infty$ & 00000 \\
\hline 00000 & .00000 & 00000 & 00000 & 0000 & 10000 & 00000 & 00000 & 00000 & 00000 & 00000 & $00 \times 00$ & 00000 & 0000 & $\infty 000$ & 00000 \\
\hline 00000 & .00000 & 00000 & 00000 & $\infty$ & .0000 & 00000 & 00000 & 00000 & 00000 & 00000 & $00 \times 00$ & 00000 & 0000 & $\infty 000$ & $00 \times 0$ \\
\hline 00000 & .00000 & 00000 & 00000 & $\infty 000$ & .00000 & 00000 & 00000 & 00000 & 00000 & 00000 & 00000 & 00000 & $\infty 000$ & $\infty 000$ & $00 \times 00$ \\
\hline 00000 & .00000 & 00000 & 00000 & $\infty 000$ & .00000 & 00000 & 00000 & 00000 & $\infty 0000$ & 00000 & 00000 & 00000 & 0000 & $\infty 000$ & 00000 \\
\hline 00000 & .00000 & 00000 & 00000 & $\infty$ & .00000 & 00000 & 00000 & 00000 & 00000 & 00000 & $00 \times 00$ & 00000 & $\infty 000$ & $\infty 000$ & 00000 \\
\hline 00000 & .0000 & $00 \times 00$ & 00000 & $\infty 000$ & .0000 & 00000 & 00000 & 00000 & 00000 & 00000 & $00 \times 00$ & 00000 & 0000 & $\infty 000$ & 00000 \\
\hline 00000 & .00000 & 00000 & 00000 & 0000 & .0000 & 00000 & 00000 & 00000 & 00000 & 00000 & 00000 & 00000 & $\infty 000$ & $\infty 000$ & 00000 \\
\hline 00000 & .0000 & 00000 & 00000 & 00000 & .0000 & 00000 & 00000 & 00000 & 00000 & 00000 & 00000 & 00000 & 0000 & $\infty 000$ & 00000 \\
\hline 00000 & .0000 & 00000 & 00000 & 0000 & .0000 & 00000 & 00000 & 00000 & 00000 & 00000 & 00000 & 00000 & 0000 & 0000 & 00000 \\
\hline 00000 & .00000 & 00000 & 00000 & 0000 & .0000 & 00000 & 00000 & 00000 & 00000 & 00000 & 00000 & 00000 & 0000 & $\infty 000$ & 00000 \\
\hline 00000 & .00000 & 00000 & 00000 & 0000 & .00000 & 00000 & 00000 & 00000 & 00000 & 00000 & 00000 & 00000 & 0000 & $\infty 000$ & 00000 \\
\hline
\end{tabular}

FIGURE 6: Simulation results of supply chain risk prevention and control index coding.

3.2.4. Calculation of Fuzzy Relationship. The corresponding fuzzy relationship between nodes is calculated from equation (5) and the relationship nodes in Table 2 . The union of fuzzy relationship matrices for prenodes is as follows:

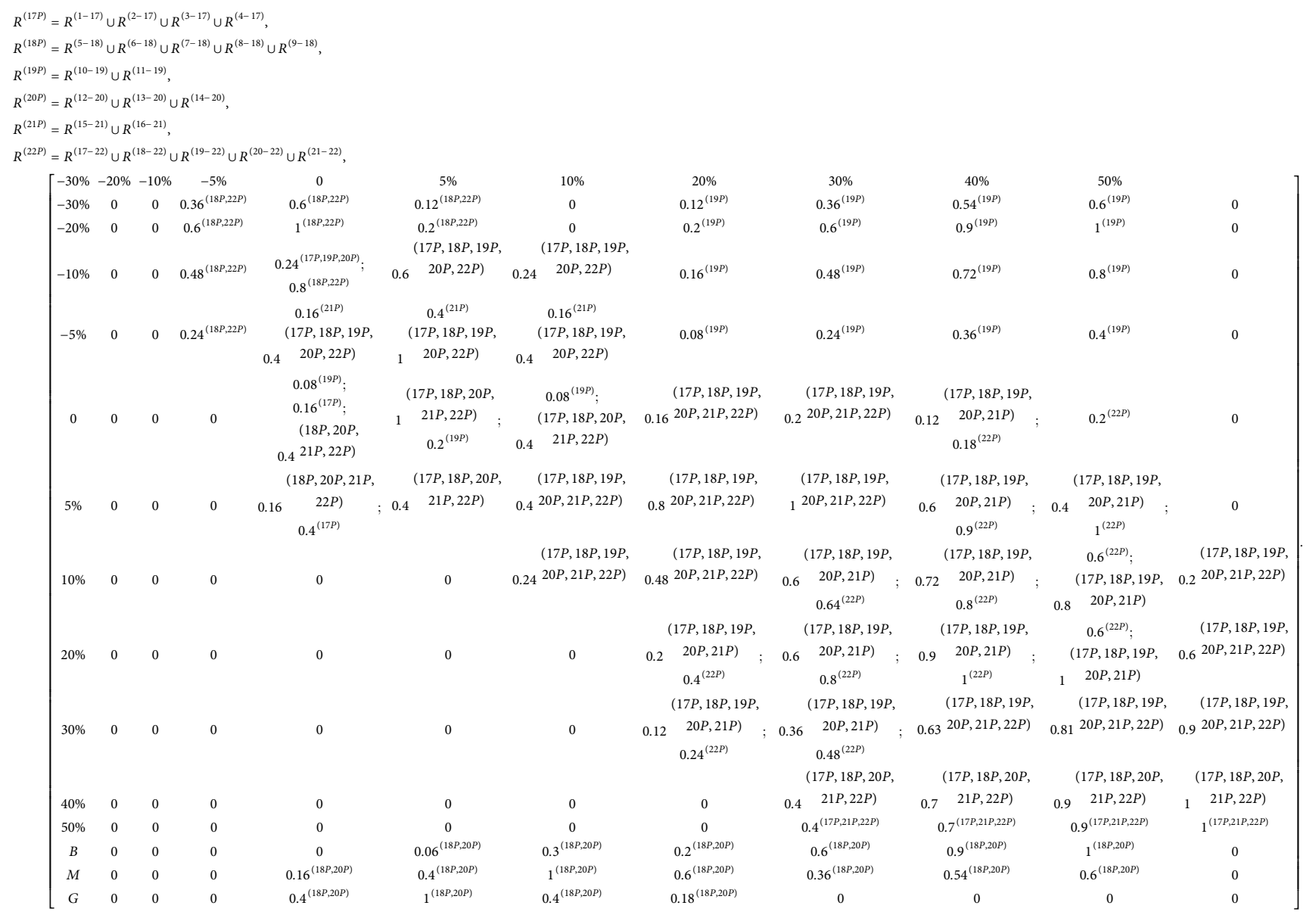

3.2.5. Calculation of Node Frequency Matrices with Prenodes.

The frequency matrices of nodes with prenodes are as follows: 


$$
\begin{aligned}
& F^{(17)}=F^{(17 P)} \circ R^{(17 P)}, \\
& F^{(18)}=F^{(18 P)} \circ R^{(18 P)} \text {, } \\
& F^{(19)}=F^{(19 P)} \circ R^{(19 P)}, \\
& F^{(20)}=F^{(20 P)} \circ R^{(20 P)} \text {, } \\
& F^{(21)}=F^{(21 P)} \circ R^{(21 P)} \text {, }
\end{aligned}
$$

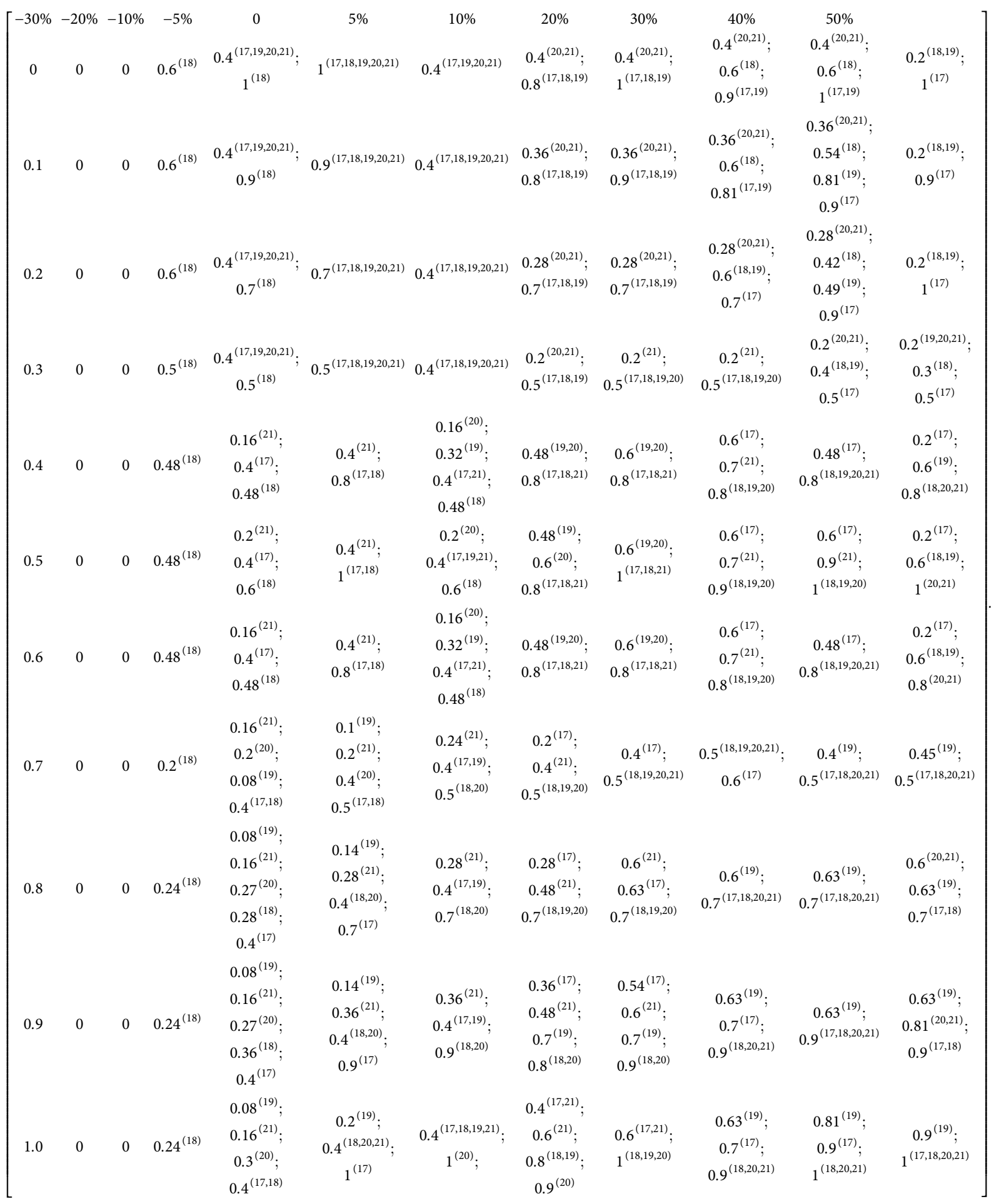

3.2.6. Calculation of Value Node Frequency Matrices. Finally, the frequency matrix of value node 22 is calculated. First, the union of the frequency matrices and the fuzzy relationship for all its prenodes is calculated. Then, the frequency matrix $F^{(22)}$ of the supply chain risk prevention and control nodes is as follows: 
TABLE 4: Supply chain risk-control strategy for the $H$ company.

\begin{tabular}{lcc}
\hline $\begin{array}{l}\text { Risk prevention } \\
\text { and control level }\end{array}$ & $\begin{array}{c}\text { Critical points of risk prevention and } \\
\text { control }\end{array}$ & $\begin{array}{l}\text { Prevention and } \\
\text { control priority }\end{array}$ \\
\hline
\end{tabular}

Procurement bidding risk, information

Class 5 management risk, market demand fluctuation risk
Specific prevention and control strategies

(1) Fully integrate internal resources and improve the bidding and purchasing mechanism of enterprises

(2) Develop information security-management systems with advanced technology architecture and improve the construction of enterprise internal network information application system

(3) Strengthen the information sharing with enterprises in the sales link, enhance the flexibility of production plans, and respond flexibly to fluctuations and variability of market demands

(1) Optimize the distribution network, outsource part of the business, improve the distribution performance, and reduce the material loss in transportation processes

Class $4 \quad$ Material loss risk II

(2) Regularly check the implementation of material storage and waste material disposal process

(1) Implement comprehensive budget management through the entire budget control process to achieve financial budget risk control

(2) Establish a daily management for enterprises by setting a cost control risk early warning system based on risk signal

Class $3 \quad$ customer financial risk, human capital risk, customer loss risk

III

(3) Establish a sound financial management system and improve the financial supervision and investment of scientific norms

(4) Strengthen personnel training and improve human capital incentive measures

(5) Implement total quality and customer-centric marketing, shorten the time to obtain demand information, and improve market reaction speeds

$$
\begin{aligned}
& F^{(22)}=F^{(22 A)} \circ R^{(22 P)}, \\
& {\left[\begin{array}{cccccccccccccc}
-30 \% & -20 \% & -10 \% & -5 \% & 0 & 5 \% & 10 \% & 20 \% & 30 \% & 40 \% & 50 \% & S U M & \\
0 & 0 & 0 & 0.6 & 1 & 1 & 0.4 & 0.8 & 1 & 1 & 1 & 1 & 7.8 \\
0.1 & 0 & 0 & 0.6 & 0.9 & 0.9 & 0.4 & 0.8 & 0.9 & 0.9 & 0.9 & 0.9 & 7.2 \\
0.2 & 0 & 0 & 0.6 & 0.7 & 0.7 & 0.4 & 0.7 & 0.7 & 0.7 & 0.9 & 1 & 6.4 \\
0.3 & 0 & 0 & 0.5 & 0.5 & 0.5 & 0.4 & 0.5 & 0.5 & 0.5 & 0.5 & 0.5 & 4.4 \\
0.4 & 0 & 0 & 0.48 & 0.48 & 0.8 & 0.4 & 0.8 & 0.8 & 0.8 & 0.8 & 0.8 & 5.84 \\
0.5 & 0 & 0 & 0.48 & 0.6 & 1 & 0.4 & 0.8 & 1 & 1 & 1 & 1 & 7.28 \\
0.6 & 0 & 0 & 0.48 & 0.48 & 0.8 & 0.4 & 0.8 & 0.8 & 0.8 & 0.8 & 0.8 & 6.16 \\
0.7 & 0 & 0 & 0.2 & 0.4 & 0.5 & 0.4 & 0.5 & 0.5 & 0.5 & 0.5 & 0.5 & 4.0 \\
0.8 & 0 & 0 & 0.24 & 0.4 & 0.7 & 0.4 & 0.7 & 0.7 & 0.7 & 0.7 & 0.7 & 5.24 \\
0.9 & 0 & 0 & 0.24 & 0.4 & 0.9 & 0.4 & 0.8 & 0.9 & 0.9 & 0.9 & 0.9 & 6.34 \\
1.0 & 0 & 0 & 0.24 & 0.4 & 1 & 0.4 & 0.8 & 0.8 & 1 & 1 & 1 & 6.64
\end{array}\right] .}
\end{aligned}
$$

In the matrix $F^{(22)}$, the sum of membership degrees for each row is calculated and then multiplied by the corresponding frequency to determine the maximum value. The membership degree is determined from equation (8), and the probability distribution and cumulative probability are calculated, as shown in Table 3.

From Table 3 , the probability of supply chain risk between $-10-5 \%$ is $30.72 \%$, that between 10 and $20 \%$ is $24.10 \%$, 
and that between 30 and $50 \%$ is $45.18 \%$. Therefore, the supply chain risk is high, and the associated probability of the value node is shown in Figure 3.

\subsection{Supply Chain Risk Prevention and Control}

\subsubsection{Hopfield Neural Network Equilibrium Point and Index Coding}

(1) Equilibrium Point of Hopfield Neural Network. The calculation results in Section 3.2 indicate that the risk probability of the supply chain is concentrated in the high-risk stage of $30-50 \%$. The risk impact level can be determined from the risk impact diagram shown in Figure 4. Five levels of supply chain risk prevention and control are designed based on the frequency fuzzy sets and membership degree of the influencing factors, and the equilibrium points of the HNN are established.

(2) Index Coding Rules. The associative ability of a DHNN can encode risk indicators and map them to neuron states. The coding rule is that the neuron state of a DHNN has two cases of 1 and -1 . When it is greater than or equal to the index value of a certain level, the corresponding neuron state is set to 1 ; otherwise, it is -1 .

3.3.2. Simulation Results and Risk-Control Strategy Analysis. The DHNN is established using the MATLAB simulation platform. Based on the five levels of risk prevention and control indicators and coding, the $H$ company's 12-month supply chain data in 2020 are coded as the input of the Hopfield neural network. The simulation results are obtained after the training. Finally, the results are compared with the equilibrium level to further verify the model rationality shown in Figures 5 and 6.

The risk factors with levels greater than or equal to 3 are set as the critical areas of risk prevention and control for the $H$ company. Therefore, the simulation results indicate that the risk prevention and control of the $H$ company should focus on financial budget risk (Class 3), cost control risk (Class 3), customer financial risk (Class 3), procurement bidding risk (Class 5), material loss risk (Class 4), human capital risk (Class 3), information management risk (Class 5), market demand fluctuation risk (Class 5), and customer loss risk (Class 3). The risk factors of Class 5 are set as level-I priority prevention and control, those of Class 4 are set as level-II, and those of Class 3 are set as level-III. The priority order is I > II > III. The $H$ company supply chain risk-control strategy is shown in Table 4.

\section{Conclusions}

Supply chain risk management is essential to research modern supply chain management, which is concerned primarily with constructing a quantified supply chain risk assessment as well as a prevention and control model. This paper proposes a supply chain risk prevention and control model based on a fuzzy influence diagram and the DHNN. The model effectively evaluates the supply chain risk, judges the risk level, and identifies the critical risk points. Finally, this paper takes the $H$ company as an example to analyze the key points and priority sequence of risk control using the prevention and control model and proposes supply chain risk-control strategies and specific measures suitable for the $H$ company. This provides a quantitative analysis for supply chain risk prevention and control.

The advantage of the proposed research method is that the information is complete, including probability estimation, alternatives, and decision-maker preference. This avoids the limitations of simple qualitative and quantitative methods while solving the difficulties of qualitative and quantitative nonsystem combinations. This provides theoretical support to accurately position key risk factors in the supply chain and has certain theoretical significance. The practical significance is to guide enterprises to clarify the key points and priority sequence of supply chain risk prevention and control, establish targeted risk prevention and control strategies, and reduce the costs of risk prevention and control. The methods employed in the paper also have some limitations. The calculation scale increases linearly with the number of risk factors. Thus, a large number of probability and utility values are required, making it difficult to model complex problems.

\section{Data Availability}

The data used to support the findings of this study are available from the corresponding author upon request.

\section{Conflicts of Interest}

The authors declare that there are no conflicts of interest regarding the publication of this paper.

\section{Acknowledgments}

This work was supported by funding from the Education Department of Guangxi Government Foundation under contract no. 2020KY05040, the National Key R\&D Program of China Function under contract no. 2020YFF0305300, and National Natural Science Foundation of China under contract no. 72104122 .

\section{References}

[1] G. P. Cachon and M. A. Lariviere, "Turning the supply chain into a revenue chain," Harvard Business Review, vol. 79, no. 3, pp. 20-21, 2001.

[2] M. Mital, M. Del Giudice, and A. Papa, "Comparing supply chain risks for multiple product categories with cognitive mapping and Analytic Hierarchy Process," Technological Forecasting and Social Change, vol. 131, pp. 159-170, 2018.

[3] G. A. Ogunranti, O. Ceryan, and A. Banerjee, "Buyer-supplier currency exchange rate flexibility contracts in global supply chains," European Journal of Operational Research, vol. 288, no. 2, pp. 420-435, 2021.

[4] J. Zic and S. Zic, "Multi-criteria decision making in supply chain management based on inventory levels, environmental 
impact and costs," Advances in Production Engineering \& Management, vol. 15, no. 2, pp. 151-163, 2020.

[5] M. Giannakis and T. Papadopoulos, "Supply chain sustainability: a risk management approach," International Journal of Production Economics, vol. 171, pp. 455-470, 2016.

[6] G. A. Zsidisir, S. M. Wagner, S. A. Melnyk et al., "Supply risk perceptions and practices: an exploratory comparison of German and US supply management professionals," International Journal of Technology, Policy and Management, vol. 8, no. 4, pp. 401-419, 2008.

[7] C. Bode and S. M. Wagner, "Structural drivers of upstream supply chain complexity and the frequency of supply chain disruptions," Journal of Operations Management, vol. 36, no. 1, pp. 215-228, 2015.

[8] I. Heckmann, "Towards Supply Chain Risk Analytics," A New Definition of Supply Chain Risk, Springer, Berlin, Germany, 2016.

[9] I. Heckmann, T. Comes, and S. Nickel, "A critical review on supply chain risk - definition, measure and modeling," Omega, vol. 52, pp. 119-132, 2015.

[10] M. A. Safayet, M. H. Islam, and S. Hhmed, "A case study on risk management in existing construction project in Bangladesh," Journal of Logistics, Informatics and Service Science, vol. 5, no. 1, pp. 1-16, 2018.

[11] S. Prakash, G. Aggarwal, A. Gupta et al., "An empirical analysis of supply chain risk and uncertainty in manufacturing sector to achieve robustness," Data Science and Analytics, Springer, Berlin, Germany, 2020.

[12] P. Kraljic, "Purchasing must become supply management," Harvard Business Review, vol. 61, no. 5, pp. 109-117, 1983.

[13] A. M. Thanigai, M. Ethirajan, J. Kandasamy et al., "Analyzing the risks of adopting circular economy initiatives in manufacturing supply chains," Business Strategy and the Environment, vol. 30, no. 1, pp. 204-236, 2020.

[14] C. Harland, R. Brenchley, and H. Walker, "Risk in supply networks," Journal of Purchasing and Supply Management, vol. 9, no. 2, pp. 51-62, 2003.

[15] A. S. Muntaka, A. Haruna, and H. Kofi Mensah, "Supply chain integration and flexibility and its impact on business performance," International Journal of Business and Management, vol. 12, no. 4, pp. 130-143, 2017.

[16] V. Seipp, A. Michel, and P. Siegfried, "Review of international supply chain risk within banking regulations in Asia, US and EU including cost efficiency proposals," Journal of Financial Risk Management, vol. 9, no. 3, pp. 229-251, 2020.

[17] L. Hezla, N. Y. Rebouh, V. Plushikov et al., "The relationship of organization failure modes and effects analysis with the safety quality for supply chain risk management," International Journal of Supply Chain Management, vol. 9, no. 2, pp. 764-771, 2020.

[18] Z. A. Collier and J. Sarkis, "The zero trust supply chain: managing supply chain risk in the absence of trust," International Journal of Production Research, vol. 59, no. 1, pp. 1-16, 2021.

[19] T. H. Nazifa and K. K. Ramachandran, "Information sharing in supply chain management: a case study between the cooperative partners in manufacturing industry," Journal of System and Management Sciences, vol. 9, no. 1, pp. 19-47, 2015.

[20] H. Jiang and C. Y. Liu, "Scheduling optimization of cloud resource supply chain through Multi-objective particle swarm optimization," International Journal of Simulation Modelling, vol. 18, no. 1, pp. 163-174, 2019.
[21] B. Savkovic, P. Kovac, D. Rodic, B. Strbac, and S. Klancnik, "Comparison of artificial neural network, fuzzy logic and genetic algorithm for cutting temperature and surface roughness prediction during the face milling process," Advances in Production Engineering \& Management, vol. 15, no. 2, pp. 137-150, 2020.

[22] X. X. Hu, S. L. Yang, and Q. Zhang, "Hierarchical influence diagrams for group decision process modeling," Systems Engineering-Theory \& Practice, vol. 31, no. 7, pp. 1312-1319, 2011.

[23] Z. P. Chang, Y. L. Wang, and L. S. Cheng, "Multiple attribute group decision making method based on fuzzy influence diagram and D-S evidence theory," Fuzzy Systems and Mathematics, vol. 28, no. 4, pp. 100-109, 2014.

[24] S. Tamimi, J. Dickman, and R. Bauman, "Risk analysis using influence diagrams," Proceedings First International Symposium on Uncertainty Modeling and Analysis, vol. 1, pp. 348353, 1990.

[25] R. D. Shachter, "Evaluating influence diagrams," Operations Research, vol. 34, no. 6, pp. 871-882, 1986.

[26] R. D. Shachter, "Probabilistic inference and influence diagrams," Operations Research, vol. 36, no. 4, pp. 589-604, 1988.

[27] J. J. Hopfield, "Neural networks and physical systems with emergent collective computational abilities," Proceedings of the National Academy of Sciences, vol. 79, no. 8, pp. 25542558, 1982. 